\title{
LA VALEUR ALIMENTAIRE DU PANGOLA (DIGITARIA DECUMBENS STENT.) ET SES FACTEURS DE VARIATION, EN ZONE TROPICALE HUMIDE.
}

\author{
M. CHENOST \\ avec la collaboration technique de \\ P. Despois, A. Grude, G. Saminadin et A. Paul-Urbain-Gieorges \\ Station de Recherches zootechniques, \\ Centre de Recherches agronomiques des Antilles et de la Guyane, I. N. R. A., \\ Petit-Bourg (Guadeloupe)
}

\section{RÉSUMÉ}

On a suivi pendant deux ans et demi l'évolution de la composition et de la valeur alimentaire de repousses de Pangola (Digitaria decumbens) en climat tropical humide (3 ooo mm d'eau par an à peu près bicn répartis sur toute l'année sauf pendant le "carême " de janvier à mars). Cette graminée fourragère, déjà largement utilisée aux Antilles, est caractérisée par une saison de forte croissance (mai à septembre) ct une saison de faible croissance (octobre à avril).

Dès les premières semaines de la repousse la plante constitue très vite des tiges et des gaines (notamment pendant la saison de forte croissance) dont la proportion varic cnsuite assez peu avec l'âge mais dont la qualité diminue rapidement (lignification, diminution de la digestibilité). La proportion de limbes, dont la qualité est supérieure à celles des tiges et relativement constante, atteint les valeurs les plus élevées pendant la saison de faible croissance époque à laquelle toutefois elle diminue le plus avec l'âge au détriment de la proportion de débris.

Il en résulte : r) que la teneur en cellulose brute du Pangola est toujours élevée (jamais inférieure à 30 p. IOo) et varie assez peu avec l'âge ; 2) que la teneur en matières azotées totales (valeurs moyennes de I I, 6 à 28 jours et de 7,0 p. Ioo à 77 jours) est peu élevée et évolue parallèlement à la proportion de limbes ; 3) que la digestibilité de la plante entière n'est jamais très élevée (70,8 à 28 jours, 59,5 p. Ioo à 77 jours), diminue relativement peu avec l'âge (o,23 points par jour) et cst assez peu affectée par la saison. La valeur énergétique nette varie de 0,73 à 0,52 UF entre 28 et 77 jours.

Les quantités de matière sèche ingérée qui varient de 55,3 à $43,2 \mathrm{~g} / \mathrm{kg} \mathrm{P}^{0,75}$ évoluent relativement peu avec l'âge mais surtout avec la saison (elles sont les plus élevées pendant la saison la plus fraîche et la plus sèche). Il semblerait que les quantités ingérées soient plus en relation avec les conditions climatiques qu'avec l'ingestibilité proprement dite de la plante. Ín effet les quantités ingérées ne sont pas ou très peu en relation avec les caractéristiques d'ingestibilité (teneur en matière sèche, teneur en matières azotées, digestibilité, vitesse de digestion dans le rumen) du fourrage.

La fumure azotée permet d'augmenter la teneur en matières azotées et la digestibilité mais n'a pas d'influence sur les quantités ingérées.

Compte tenu de sa qualité modeste et de l'évolution relativement réduite de celle-ci avec l'âge, le Pangola peut être exploité avec une certaine souplesse et c'est plus les aspects saisonniers et son potentiel de production qui vont permettre de décider de son type d'exploitation pour la recherche du compromis optimum production de matière sèche $\times$ qualité. Dans une optique d'affouragement en vert on cherchera, pendant la saison de forte croissance, à tirer davantage parti du potentiel élevé de production que de la qualité en exploitant suivant des rythmes plus 
lents alors que pendant la saison de faible croissance il conviendrait plus de s'attacher à Ia qualité qu'à la productivité, de toute façon plus faible, en cherchant à ne pas allonger le rythme d'exploitation. Ceci implique soit des reports de récolte (ensilage) soit l'intervention dans le système fourrager de plantes ayant un rythme de croissance différent de cclui du Pangola.

\section{INTRODUCTION}

On sait l'intérêt que présente le Pangola (Digitaria decumbens) pour l'intensification de l'élevage aux Antilles grâce à sa facilité d'implantation et d'exploitation et à sa potentialité de production élevée (OAKEs, I960; VINCENTE-CHANDLER et al., I96I, I964; OSBourn, I969). Malheureusement, comme celle de la plupart des graminées tropicales, (Mrsson et McLEOD, I970), sa valeur alimentaire est médiocre ; elle a été mesurée par un certain nombre d'auteurs (BUTTERWORTH ct al., Ig6r; ButTerworth, I964; Grieve et Osbourn, I965; Sherrod et al., I967; 'Thomas et McLAREx, I97 I HUANG ChIA YEH, I965...) mais généralement sur des périodes courtes et dans des zones à pluviométrie annuelle comprise entre I 200 et $2000 \mathrm{~mm}$ et à saison sèche marquée, l'accent ayant été mis surtout sur la composition et la digestibilité de la plante et beaucoup moins sur son ingestibilité (aptitude propre d'un fourrage à être ingéré par l'animal à qui on le présente à volonté).

Dans une note précédente (CHENOST, I972) des mesures effectuées tout au long de l'année en zone tropicale humide (3000 $\mathrm{mm}$ d'eau par an à peu près correctement répartis sur l'année) nous avaient permis d'observer des variations importantes dans les quantités de fourrage vert ingérées à volonté par des boucs, ces variations semblant être liées non aux caractéristiques de la plante mais plus vraisemblablement à l'influence du climat sur l'appétit des animaux. BuT'TERWOR'TH et al. (I96I), qui notent également des alternances saisonnières marquées dans les quantités de Pangola ingérées par des vaches en lactation à Trinidad en zone à saison sèche plus marquée, pensent d'ailleurs que la teneur en matière sèche du fourrage n'est pas le seul facteur responsable de ces variations et que l'état de confort de l'animal serait, en saison sèche, favorable à une ingestion plus importante de fourrages.

Nous regroupons ici l'ensemble des mesures effectuées pendant 2 ans et demi (I84 échantillons) dans le but d'essayer d'analyser les variations de la valeur alimentaire du Pangola (Digitaria decumbens) et leurs causes.

\section{MATÉRIEI, ET MÉTHODES}

\section{Prairies}

Nous avons mesuré l'évolution tout au long de l'année de la digestibilité et des quantités ingérées de deux catégories de repousses de Pangola :

- d'une part "d'âge constant" ( 30 jours et 50 jours), provenant de deux prairies exploitées en continu, subdivisées l'une en 30 parcelles, l'autre en 50 parcelles, une parcelle correspondant à la surface fauchée chaque jour ;

-. d'autre part "d'âge variable ", allant de 28 à 77 jours provenant d'une prairie exploitée à partir de 28 et jusqu'à 77 jours après la fauche d'égalisation précédente. 
La prairic exploitée à 30 jours d'âge recevait $840 \mathrm{~kg}$ d'N et $840 \mathrm{~kg}$ de $\mathrm{K}_{2} \mathrm{O}$ par hectare et par an, celle exploitée à 50 jours d'âge recevait $350 \mathrm{~kg}$ d' $\mathrm{N}$ et $350 \mathrm{~kg}$ de $\mathrm{K}_{2} \mathrm{O}$ par hectare et par an ; la quantité de $\mathrm{P}_{2} \mathrm{O}_{5}$ était respectivement égale à 250 et I $30 \mathrm{~kg}$ par hectare et par an.

La prairie exploitée par cycles successifs d'âge variable recevait une fumure de $80 \mathrm{~kg}$ d' $\mathrm{N}$ et de $80 \mathrm{~kg}$ de $\mathrm{K}_{2} \mathrm{O}$ à chaque fauche d'égalisation, soit $400 \mathrm{~kg}$ d'N et $400 \mathrm{~kg}$ de $\mathrm{K}_{2} \mathrm{O}$ au total par an compte tenu du nombre d'exploitations cffectuécs, $1_{2} \mathrm{O}_{5}$ était apporté une fois par an (250 $\left.\mathrm{kg}\right)$.

Les fourrages ont été distribués à 3 lots de 6 boucs ( 4 en cage à digestibilité, 2 en cage au sol). Un lot a reçu les repousses d'âge variable ( 13 cycles d'exploitation successifs pendant deux ans, soit 67 échantillons de fourrage); les deux autres lots ont reçu en permanence pendant un an et demi les repousses d'âge constant, soit 59 échantillons de fourrage âgé de 30 jours et 58 échantillons de fourrage âge de 50 jours. Les repousses cl'àge constant étaicnt distribuées par ailleurs à des chèvres en lactation (CHENOST et JOUSQUET, I974).

Le fourrage frais, fauché le matin entre 7 et 9 heures, était distribué a volonté (ro p. Ioo de refus) à l'auge en deux repas, l'un au début de la matinée, l'autre dans le milieu de l'après-midi.

\section{Animanx}

Les boucs utilisés étaient de race Alpine (Chamoisée et Saanen). Ils avaient été importés de lirance en I 966 ou étaient nés en Guadeloupe. Entiers pour la plupart, ils étaient âgés de 2 à 4 ans et pesaient entre 37 ct $65 \mathrm{~kg}(49,5 \mathrm{~kg}$ en moyenne).

\section{Mesures}

Les quantités de matière sèche ingérées ont été mesurées chaque jour, sauf le dimanche, par pesée des quantités offertes et refusées et détermination de la teneur en matière sèche du fourrage distribué et des refus. Chaque résultat correspond à la moyenne des consommations journalières individuelles de 6 boucs pendant Ja période du lundi au samedi.

La digestibilité de chaque catégorie de fourrage vert à été mesurée avec les quatre boucs en cage ; chaque résultat correspond à la digestibilité moyenne du fourrage offert pendant la période clu lundi au samedi.

Un échantillon représentatif clu fourrage offert et du fourrage refusé a été constitué pour chaque période de mesure; nous en avons fait l'analyse morphologique (pesée des différents organes, limbes, tiges plus gaines, épis, débris, pris isolément après séparation et séchage à l'étuve) et l'analyse chimique (teneur en cendres, en azote et collulose brute Weende).

On a mesuré en outre:

- la digestibilité en sachets de nylon au bout de $2+$ et 72 heures (DEMARQUilly ct ChenosT, r 969) et la digestibilité in vitro (TILLEY et TERRY, I963) de 24 échantillons correspondant à des plantes récoltées à différentes saisons et choisics de telle manière juc leur proportion de limbes, leur digestibilité in vivo et les quantités de matière sèche qui cn étaient ingérées étaient représentatives cle celles de l'ensemble des échantillons de fourrage.

- la digestibilité in vitro des limbes et des tiges + gaines de 23 échantillons correspondant à des plantes de même âge et de même digestibilité in vivo mais récoltées ì des saisons différentes.

- enfin la digestibilité in vitro des limbes et des tiges + gaines de 12 échantillons, constitués pendant le mois d'aồt, de fourrages âgés de 2 I à 56 jours et ayant reçu soit la fumure de $800 \mathrm{~kg}$ soit celle de $350 \mathrm{~kg}$.

Le régime de la vache fistulée utiliséc pour la digestibilité in vitro et la digestibilité en sachets était constitué d'une luzerne de bonne qualité broyéc et agglomérée venant de métropole, distribuée à volonté, et de repousses de Pangola âgées de fo à 50 jours distribuées en vert en quantité limitée (ro kg de fourrage vert par jour).

\section{RÉSULTATS}

\section{Composition chimique et morphologique}

- la teneur en matière sèche des échantillons de fourrage vert varie dans des limites très larges (I3,6 à 27,0 p. I00). Elle augmente régulièrement avec l'âge (tabl. I) et ne dépand pas significativement de la saison; les teneurs les plus élevées sont toutefois observées pendant les mois d'avril à septembre, saison de forte croissance pendant 
laquelle 1a plante épie. Elle présente des variations journalières ou même hebdomadaires qui sont très importantes et qui peuvent être plus grandes que celles dues à l'âge et à la saison.

- La proportion de tiges + gaines est toujours très élevée et varie assez peu avec l'âge : 50 p. Ioo à 28 jours, 60 p. Ioo à 56 jours (tabl. I). Ėlle varie surtout avec la saison (fig. I) et c'est pendant la saison de forte croissance qu'elle est la plus élevée.

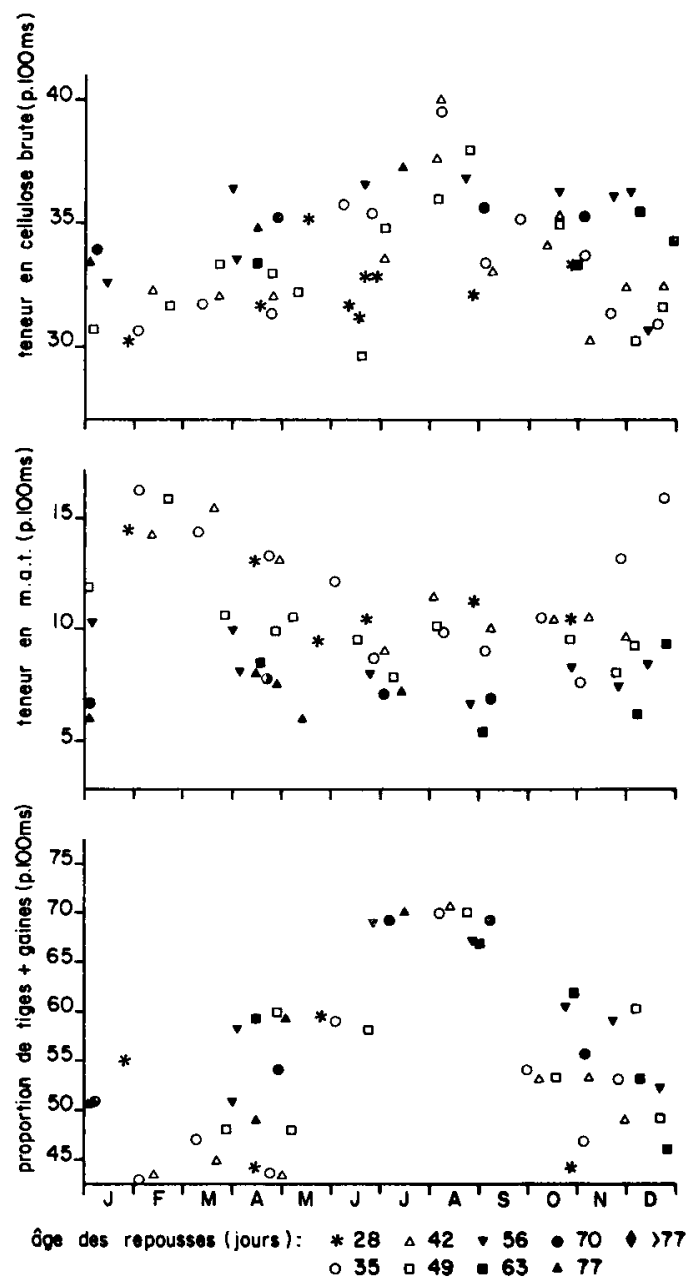

FIG. I. - Tariations saisonnières de la teneur en cellulose brute, de la teneur en matières azotées at de la proportion de tiges de repousses de Pangola d'áge variable

Sa variabilité à âge et à saison donnés est très importante (fig. 2) et elle est liée de façon très lâche à l'âge.

- La proportion de limbes diminue avec l'âge de la plante surtout pendant la saison de ralentissement de la croissance (octobre à avril) (fig. 2) pendant laquelle le Pangola émet des stolons alors que pendant la période d'épiaison même les jeunes 
repousses sont pauvres en limbes. C'est ainsi que la proportion de débris (parties flétries ou mortes) qui 'augmente avec 1'âge pour atteindre la valeur moyenne très élevée de 16 p. Ioo dans le cas des repousses de 77 jours est plus importante pendant la saison de faible croissance pendant laquelle les petites feuilles des stolons rampants flétrissent vite avec l'âge en raison du feutrage compact important ainsi constitué sous la partie aérienne proprement dite. A âge égal la proportion de limbes varie avec la saison ; elle commence à diminuer en avril au moment de la reprise de croissance du Pangola pour atteindre son minimum en juillet-aồt et réaugmenter en septembre.

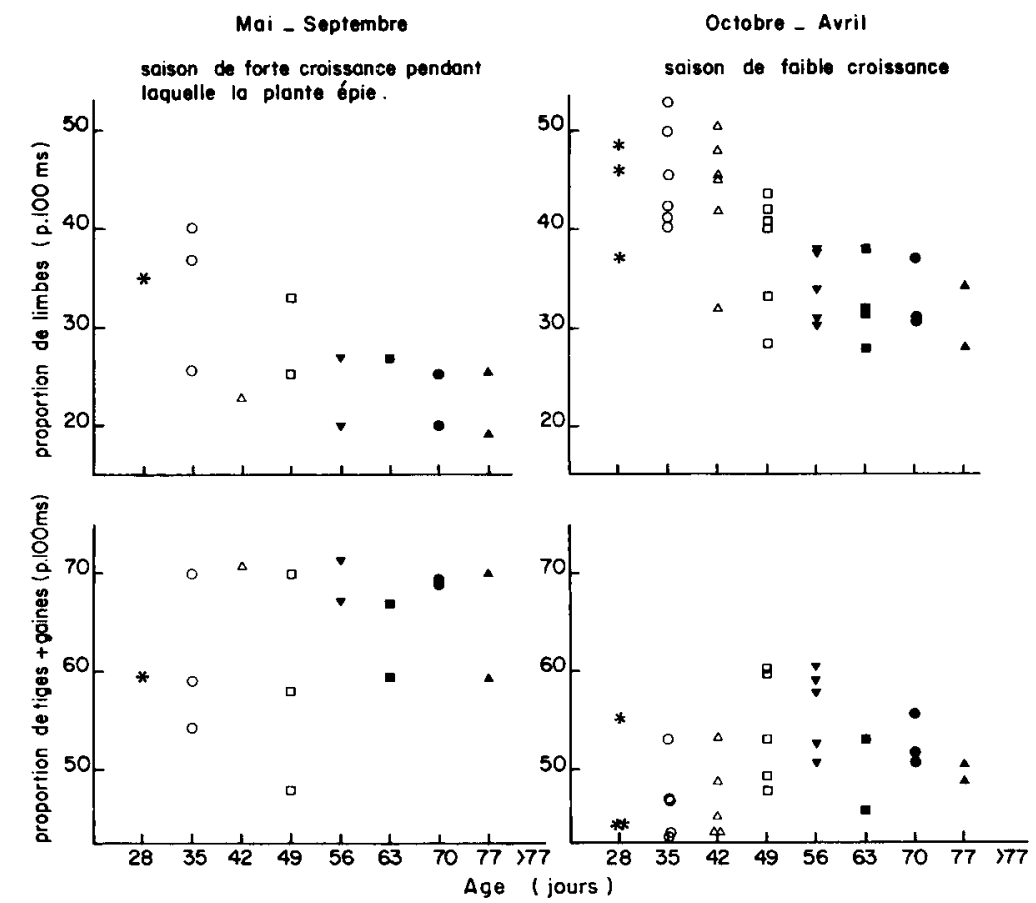

FIr. 2. - Variations suivant l'âge et la saison de la composition morphologique de repousses de Pangola (Digitaria decumbens)

- La teneur en matières azotées totales varie dans de très larges limites (5, I à 16,5 p. I00, valeurs extrêmes) mais est en moyenne assez faible. Elle diminue régulièrement avec l'âge et passe de II,6 p. Ioo à 28 jours à 7,o p. Ioo à 77 jours (tab1. I). A âge égal elle varie suivant la saison (fig. I), les valeurs minima se situant entre juin et septembre, période pendant laquelle la croissance du Pangola est intense (épiaison à 30-35 jours après la fauche précédente). Comme la teneur en limbes avec laquelle, d'ailleurs, elle est étroitement liée $(r=+0,675 n=\mathrm{I} 43$, ensemble des échantillons) c'est pendant la saison de faible croissance que ses variations dues à l'âge sont les plus importantes. Enfin elle présente une liaison significative et négative avec la teneur en matière sèche $(r=-0,622)$.

- La teneur en cellulose brute est toujours très élevée et varie dans des limites relativement faibles $(29,7$ à 40,3$)$. Elle augmente avec 1'âge de 32,4 p. Ioo en moyenne 
VAIEUR ALIMENTAIRE DU PANGOI.A

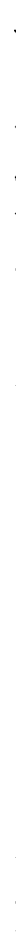
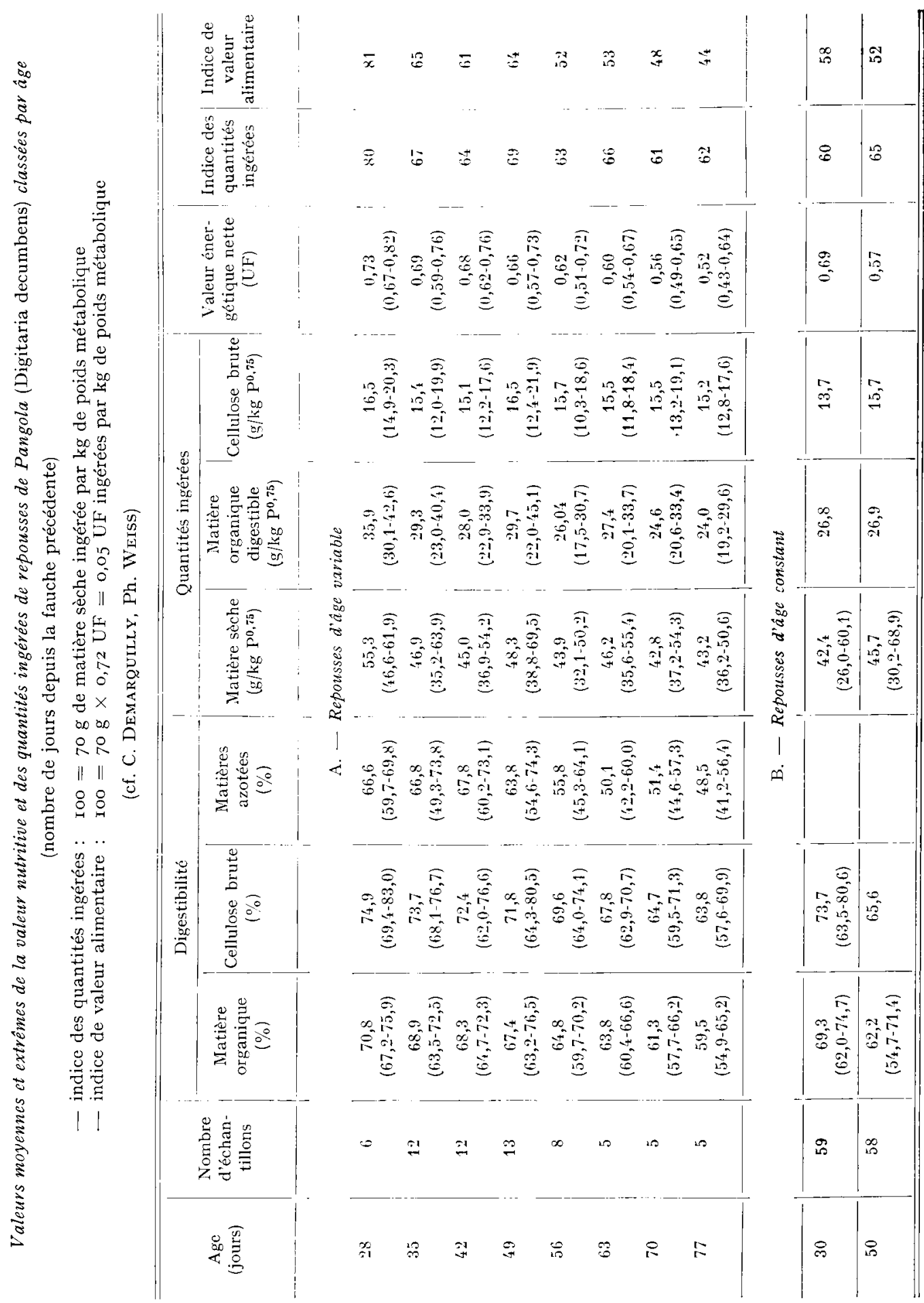

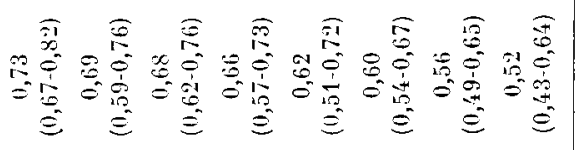

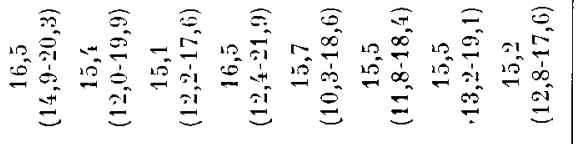

$\stackrel{8}{=} \stackrel{1}{0}$

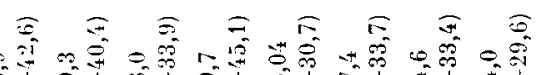

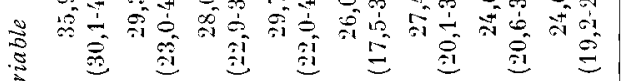

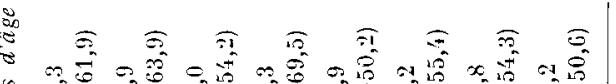

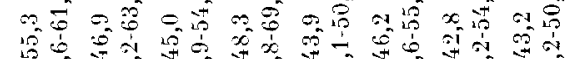

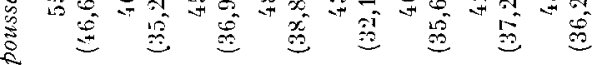

(2)

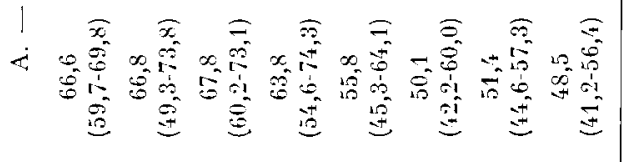

$\stackrel{2}{\rightarrow}$

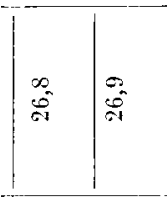

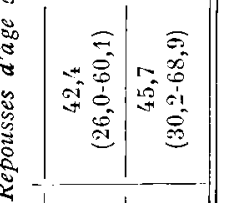

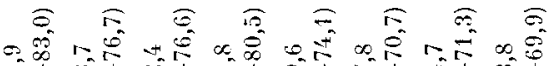

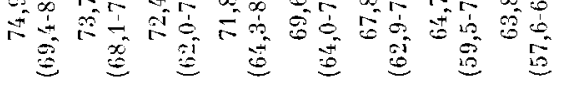

i

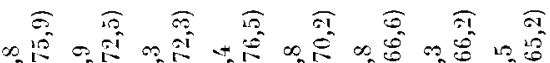

$\therefore \rightarrow$
0 in

है की है है है है

\begin{tabular}{|c|c|}
\hline 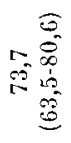 & 80 \\
\hline 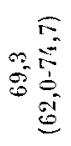 & 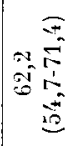 \\
\hline 周 & 品 \\
\hline 8 & ถิ \\
\hline
\end{tabular}




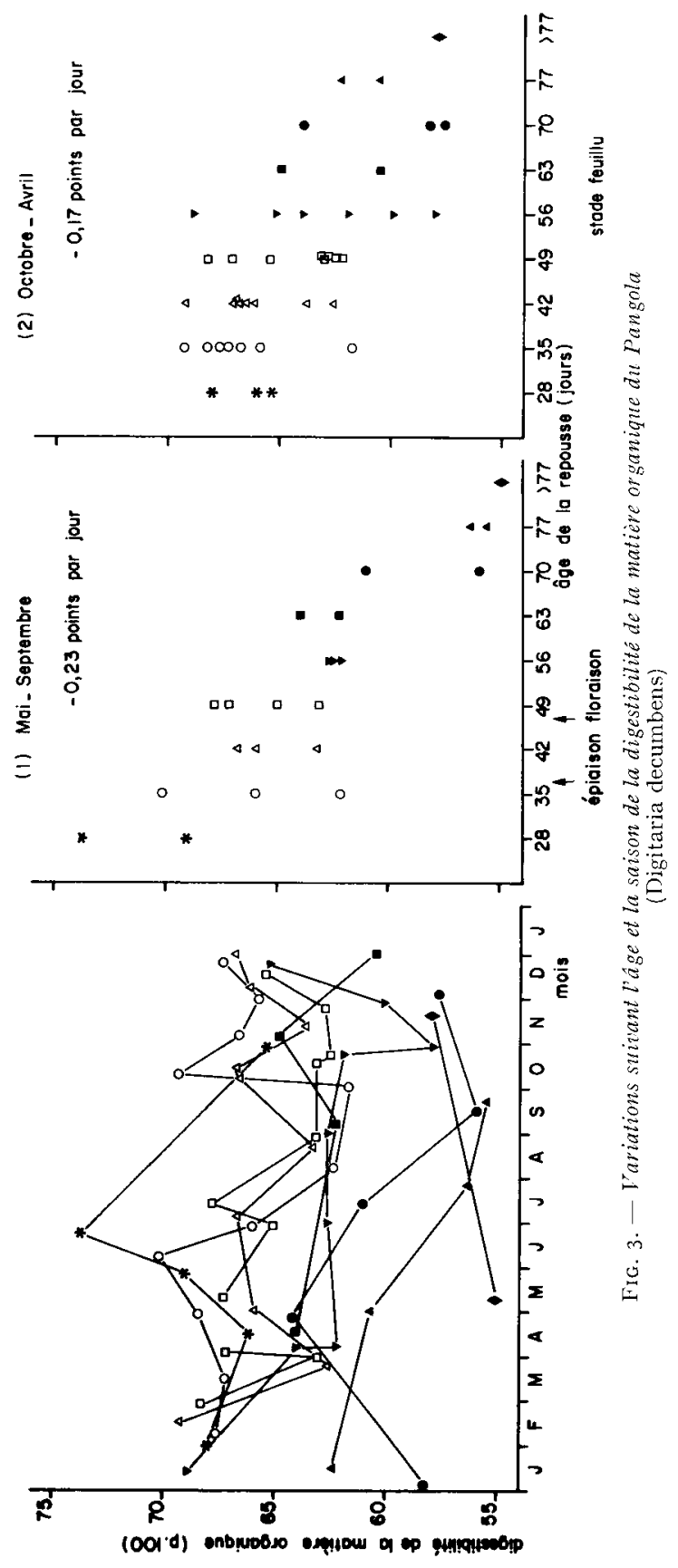


à 28 jours à 36,2 p. Ioo en moyenne à 70 jours (tabl. I). Les valeurs les plus élevées sont observées pendant les mois de juin à septembre (fig. I).

- La teneur en cendres varie dans des limites importantes $(4,5$ à $\mathrm{I} 2,3)$ et diminue avec l'âge (tabl. I).

La comparaison des différences de composition entre les échantillons 28 et 49 jours (système âge variable) d'une part et entre les échantillons 30 et 50 jours (systène âge constant) d'autre part permet de penser à une influence de la fumure azotée. En effet les quantités d'engrais azoté apportées par jour de végétation sont différentes suivant les deux systèmes d'exploitation, les repousses de 50 jours ayant reçu moins d'azote que les repousses de 49 jours (tabl. r). Cette influence apparait surtout sur la teneur en matières azotées qui ne diminue que de $I, 8$ points dans le système âge variable alors qu'elle diminue de 5,4 points dans le système âge constant (faible fumure). Ceci confirme d'ailleurs les résultats obtenus par SAI.ETTE (I970).

\section{Digestibilité}

Digestibilité et composition morphologique ou chimique.

- La digestibilité de la matière organiquc diminue régulièrement avec l'âge, de 70,8 p. Ioo à 28 jours, à 59,5 p. Ioo à 77 jours (tabl. 2). On peut dégager une relation significative $(\mathrm{P}<0, \mathrm{or})$ liant la digestibilité de la matière organique $(y)$ au nombre de jours $(x)$ de végétation de la repousse:

$$
y=77,19-0,217 x \pm 3,09 \quad(r=-0,709 \quad n=67)
$$

de laquelle il apparaît que la digestibilité diminue en moyenne de 0,22 points par jour.

La diminution journalière de la digestibilité varie suivant la saison (fig. 3). Elle est en effet plus importante pendant la saison de forte croissance $(0,23$ point par jour) que pendant la saison de faible croissance (O,I7 point par jour) mais l'interaction âge $X$ saison n'est pas significative (tabl. 3 ).

A âge égal la digestibilité a tendance à être plus faible pendant la période de forte croissance (fig. 3), cette influence de la saison n'étant toutefois pas significative (tabl. 3).

Les variations à un âge donné sont importantes (tabl. 2) et cela plus particulièrement pendant la saison de faible croissance (fig. 3). D'ailleurs, si on regroupe les mesures non plus par âge mais par classe d'âge précédant ou suivant le stade début épiaison, pris comme origine pour les repousses épiant, on n'améliore pas la relation liant la digestibilité au stade physiologique de la plante, celle-ci diminuant linéairement.

Nous avons reporté sur la figure 4 les variations saisonnières de la proportion et de la digestibilité in vilro des limbes et des tiges + gaines de 23 échantillons de digestibiiité in rivo comparables. Dans le cas des repousses feuillues ou au stade montaison fauchées tous les 30 jours la digestibilité des limbes est voisine de celle des tiges -t gaines et à peu près constante tout au long de l'année, la diminution de la proportion de limbes pendant la période de forte croissance n'entraîne donc pas une diminution élevée de la digestibilité de la plante entière. Dans le cas des repousses fauchées tous les 50 jours la diminution de la digestibilité des tiges + gaines et l'aug- 
TABIEAU 3

Influence de la saison et analyse de l'influence de l'âge te de la saison sur la teneur en matières azotées digestibles, la digestibitité de la matière organique et l'acceptabilité du Pangola (Digitaria decumbens)

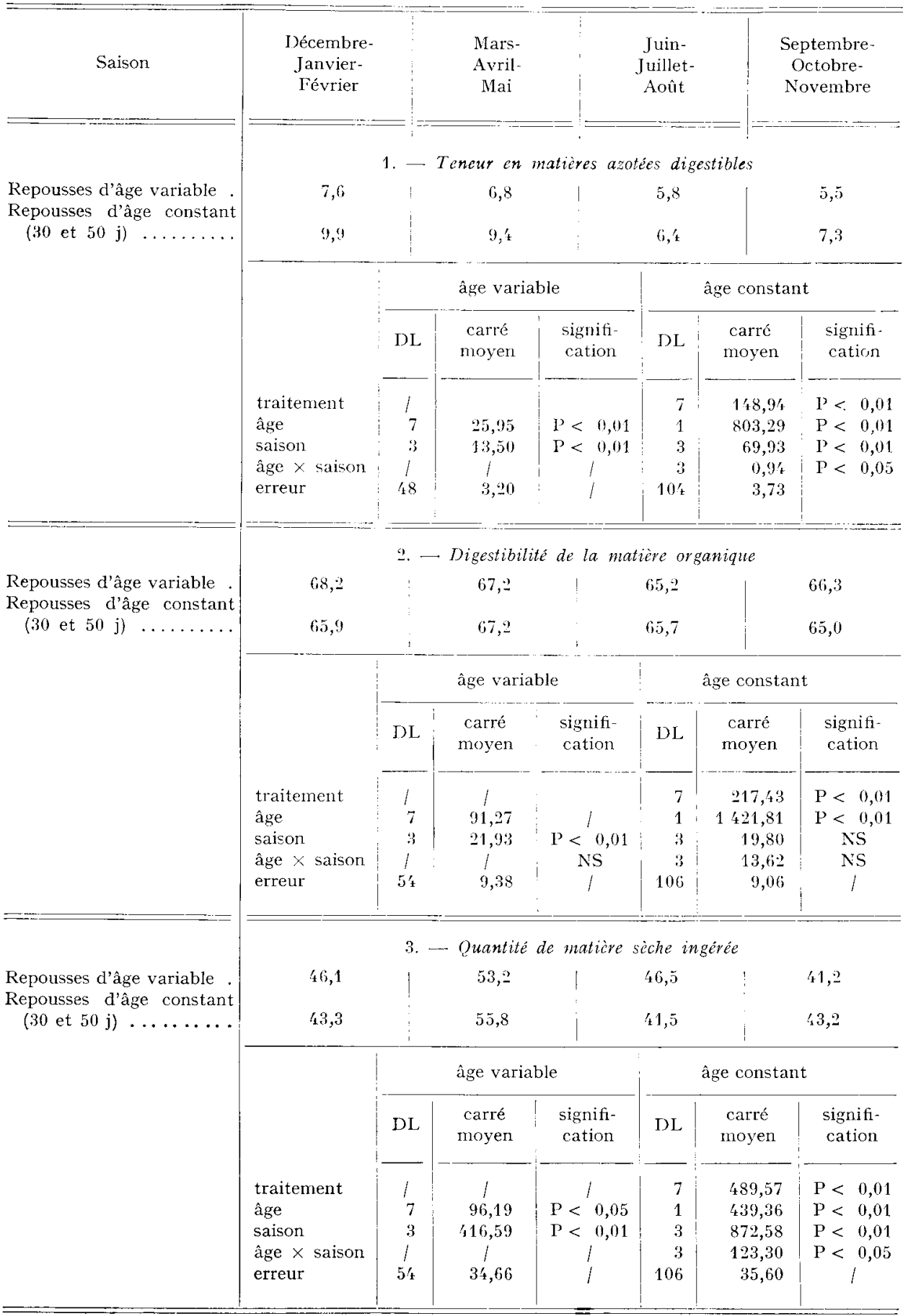


mentation de leur proportion pendant la saison de forte croissance entraîne une diminution de la digestibilité de la plante entière, la digestibilité des limbes ne diminuant quant à elle que de façon modérée. C'est ainsi que pendant la période de mai à septembre les différences de digestibilité entre les repousses de 30 jours en montaison début épiaison et les repousses de 50 jours en floraison ont tendance à être les plus importantes.

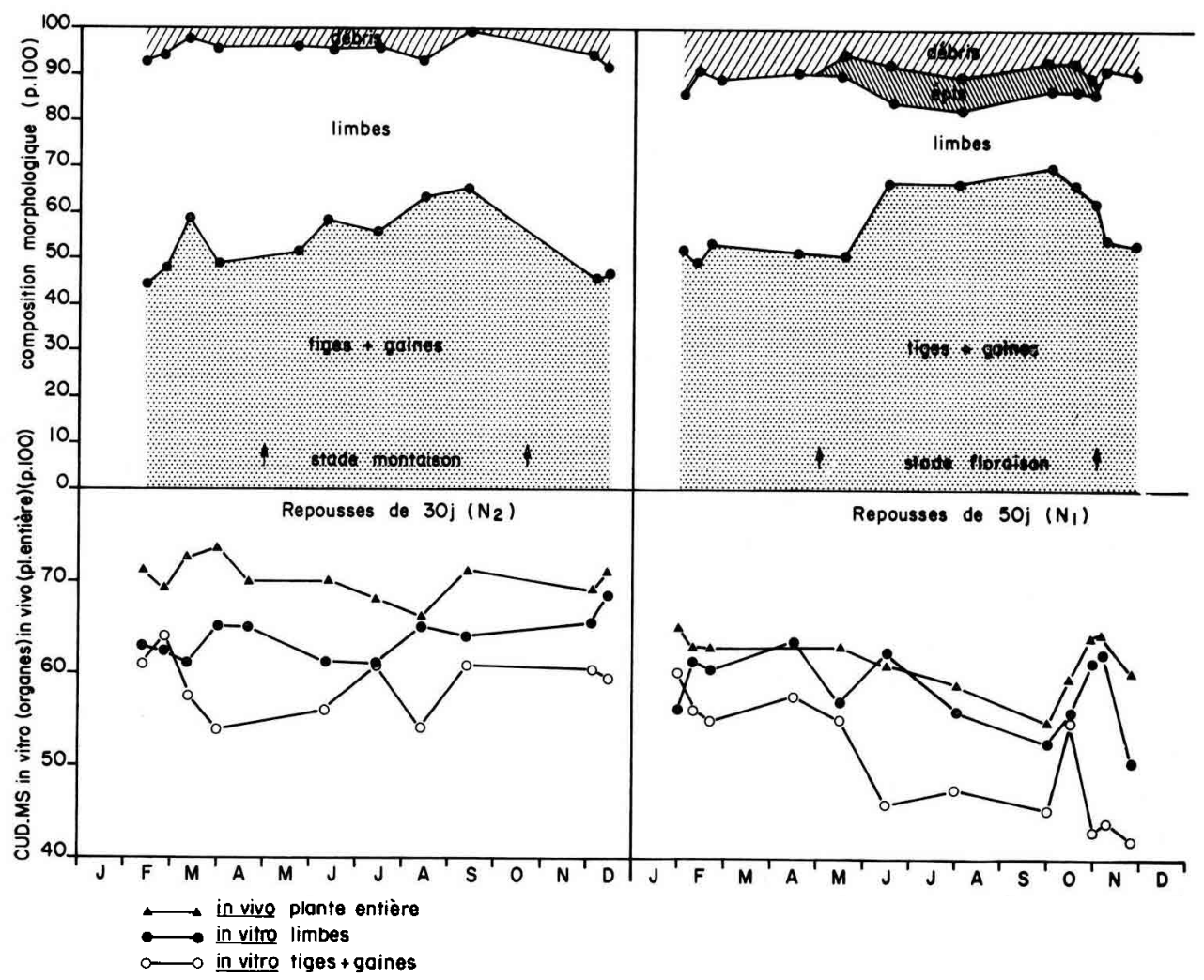

Fig. 4. - Variations saisonnières de la composition morphologique et de la digestibilité in vitro des organes de repousses de Pangola fauchées soit tous les 30 jours soit tous les jo jours

La proportion de tiges + gaines atteint très vite une valeur élevée dès les premières semaines de croissance, les limbes se transformant alors pour partie en débris lorsque la plante vieillit. Ceci explique que la digestibilité de la matière organique n'est qu'en relation (négative) lâche mais cependant significative ( $r=-408 \quad n=\mathrm{I} 53$ ) avec la proportion de tiges + gaines et (positive) avec la proportion de limbes $(r=0,539 \quad n=\mathrm{I53})$. Cette relation entre la digestibilité et la composition morphologique ne devient plus étroite que pendant la saison de forte croissance $(r=0,632$ $n=67$ avec les limbes) surtout en raison de la proportion plus élevée de tiges + gaines à cette époque et de la diminution marquée de leur digestibilité avec l'âge (fig. 5). C'est en fait cette diminution de la digestibilité des tiges + gaines qui à cette époque est l'élément principal de la diminution de la digestibilité de la plante 
entière. Malgré une diminution de la proportion de limbes plus marquée pendant la saison de faible croissance la diminution journalière de la digestibilité de la plante est plus faible parce que la proportion des tiges + gaines est moins importante.

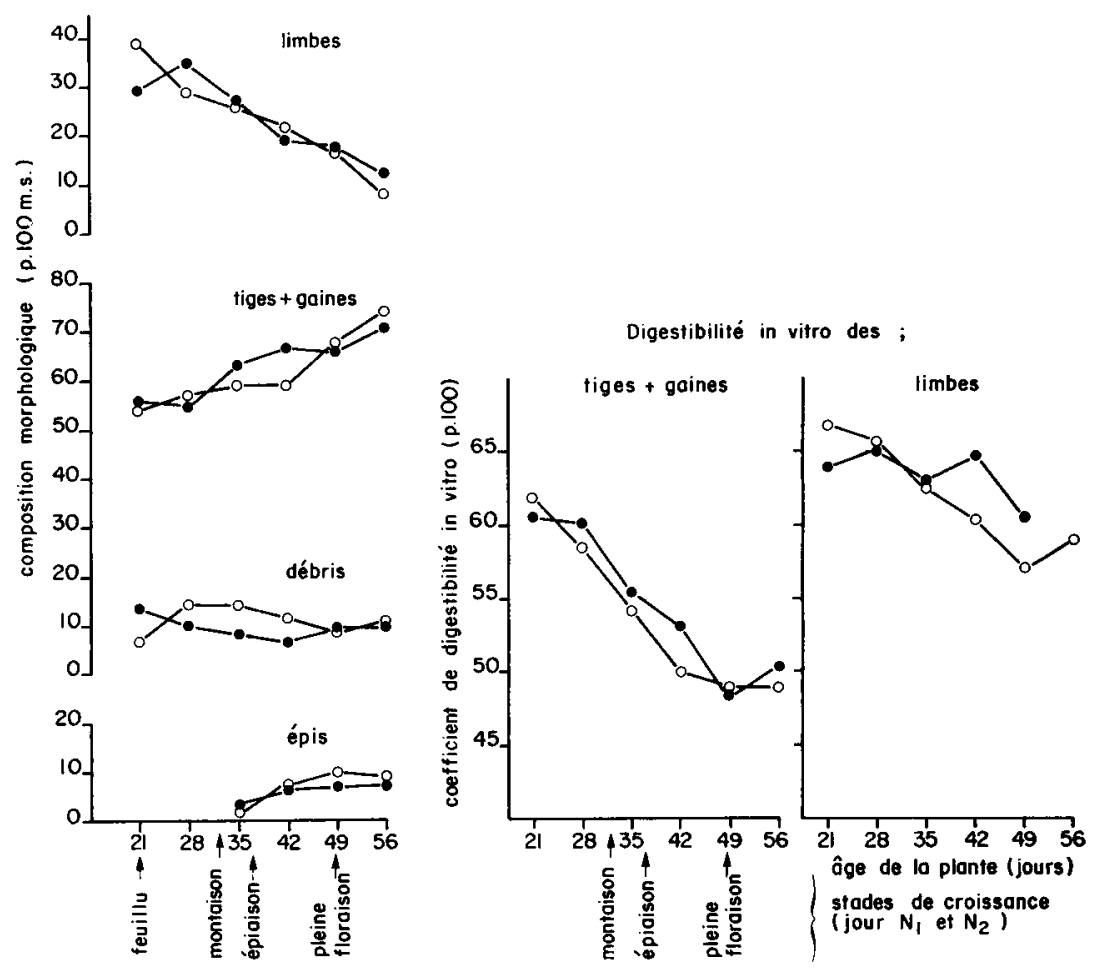

FIG. 5. - Composition morphologique, réalisation de stades de croissance, digestibilité in vitro des organes de la plante (Pangola) suivant l'áge et le niveau de fertilisation azotée (saison de forte croissance)

$\bullet \longrightarrow \mathrm{N}_{2}=80 \mathrm{~kg} \mathrm{~N}$ à la fauche de préparation
$\mathrm{O} \longrightarrow \mathrm{N}_{1}=50 \mathrm{~kg}$.

- Pour 1'ensemble des échantillons, la digestibilité de la matière organique est liée mais de façon très lâche $(r=0,309 n=\mathrm{I} 53)$ et non significative à la teneur en matière sèche du fourrage, cette relation pouvant s'expliquer par le fait que la teneur en matière sèche augmente quand la plante vieillit et que sa digestibilité diminue. Elle présente une liaison significative mais lâche avec la teneur en matières azotées $(r=0,520 \quad n=$ I53) mais aucune liaison avec la teneur en cellulose brute qui varie entre de trop faibles limites.

- La fumure azotée a une influence sur la digestibilité de la matière organique. En effet dans le système d'exploitation à âge constant la digestibilité diminue en moyenne de 69,3 p. Ioo à 30 jours à 62,2 p. Ioo à 50 jours alors que dans le système âge variable elle ne diminue que de 70,8 p. I0o à 28 jours à 67,4 p. I-Oo à 49 jours. Cette influence doit être due à une action bénéfique de la fertilisation sur la digestibilité des organes de la plante plutôt que sur leur proportion (fig. 5) ou encore sur la date de réalisation des stades de croissance qui interviennent au même âge après la fauche précédente (fig. 5). 
- La digestibilité des matières azotées dépend de leur teneur dans la plante. C'est ainsi que la teneur en matières azotées digestibles (MAD) des 183 échantillons est liée à la teneur en matières azotées totales (MAT) par l'équation :

$$
\operatorname{MAD}=0,9 \mathrm{I} 6 \mathrm{MAT}-2,895 \pm 0,495 \quad(r=0,989 \quad n=\mathrm{I} 83)
$$

relation voisine de celle établie par MILFORD et Minson (I965) sur 2 r8 fourrages tropicaux d'espèces et de variétés différentes. La teneur en MIAD est comprise entre les valeurs moyennes de 7,7 à 28 jours et $3,4 \mathrm{p}$. roo à 77 jours c'est-à-dire des valeurs très faibles.

- La digestibilité de la cellulose brute est relativement élevée puisqu'elle est comprise en moyenne entre 74,9 à 28 jours et 64,8 p. Ioo à 77 jours pour l'ensemble des échantillons d'âge variable. Dans le cas des repousses jeunes elle est légèrement plus élevée pendant la saison de forte croissance que pendant la saison de faible croissance pendant laquelle la teneur en cellulose brute a été plus faible (tabl. 2 ). La fumure azotée a eu une influence sur la digestibilité de la cellulose brute puisque celle-ci a été de 7 I, 8 p. Ioo dans le cas des repousses de 49 jours (système âge variable) et de 65,6 dans le cas des repousses de 50 jours (système âge constant) (tabl. I). La digestibilité de la cellulose brute est en liaison très lâche $(r=0,295 \quad n=67)$ avec la teneur en cellulose brute et en liaison moins lâche avec l'âge de la repousse $(r=0,679$ $n=67)$ et avec la teneur en feuilles $(r=+0,596 \quad n=67)$.

\section{Prévision de la digestibilité}

A partir de 24 échantillons de caractéristiques différentes nous avons comparé les coefficients de corrélation liant la digestibilité de la matière sèche à la teneur en matières azotées totales, à la teneur en cellulose brute de Weende, à la proportion de limbes, à la digestibilité sachets 72 heures et à la digestibilité in vitro 48 heures. Nous avons obtenu le classement suivant.

$\begin{array}{ll}\text { sachets } 72 \mathrm{~h} & r=0,8 \mathrm{I} 8 \\ \text { MAT } & r=0,807 \\ \text { DIV } 48 \mathrm{~h} & r=0,728 \\ \text { limbes } & r=0,657 \\ \text { cellulose brute } & r=0,398\end{array}$

La teneur en matières azotées totales constitue donc après les sachets $72 \mathrm{~h}$ un critère relativement intéressant de prévision de la digestibilité de la matière organique.

\section{Quantités ingérées}

Quantités de matière sèche ingérées.

- Les quantités de matière sèche ingérées ne dépendent pas de la teneur en matière sèche de la plante, que l'on prenne les résultats dans leur ensemble ou par saison ou encore à digestibilité donnée.

- Elles varient assez peu avec l'âge de la plante puisqu'elles diminuent d'une valeur moyenne de $55,3 \mathrm{~g} / \mathrm{kg} \mathrm{P}^{0,75}$ à 28 jours à une valeur moyenne de $42,4 \mathrm{~g} / \mathrm{kg}$ $\mathrm{P}^{0,75}$ à 77 jours (liaison non significative dans le cas des 67 repousses d'âge variable). 
- En revanche les quantités de matière sèche ingérées varient avec la saison (tab1. 3). C'est pendant les mois de février-mars-avril qu'elles sont les plus élevées et pendant les mois de juillet à décembre qu'elles sont les plus faibles. Dans le cas des repousses d'âge variable l'amplitude maximum due à la saison est de $\mathrm{I} 4,3 \mathrm{~g} / \mathrm{kg}$ $\mathrm{P}^{\mathbf{0}, 75}$ pour des repousses âgées de 35 jours alors que celle due à $1^{\prime}$ âge de ( 28 à 77 jours) n'était que de $7,2 \mathrm{~g} / \mathrm{kg} \mathrm{P}^{0,75}$ pendant les mois de mars I969 et avril I970 (CHENost, I972).

- Le fait que les différences de quantités ingérées entre les repousses de 30 et 50 jours (système âge constant) soient en faveur des repousses de 50 jours et moins grandes que les différences de quantités ingérées entre les repousses de 28 et de 49 jours (système âge variable) (tabl. 2) sont difficiles à expliquer mais contribuent à faire penser que la fumure azotée n'a pas d'influence sur les quantités ingérées alors qu'elle en a sur la digestibilité et sur la teneur en matières azotées digestibles.

- Les quantités de matière sèche ingérées (repousses d'âge variable) sont en liaisons très lâches avec la digestibilité de la matière organique $(r=0,427 \quad n=67)$ avec la teneur en matières azotées $(r=0,409 n=67)$ et nulle avec la teneur en cellulose brute. La liaison qu'elles présentent avec la proportion de limbes $(r=0,174$ $n=$ I53 pour l'ensemble de tous les échantillons d'âge constant et d'âge variable) est plus étroite lorsqu'on ne considère que les repousses d'avril à octobre $(r=0,328$ $n={ }^{6} 67$ ) et ceci plus particulièrement dans le cas des repousses d'âge variable $(r=0,53 \mathrm{I} \quad n=33)$.

\section{TABLEAU 4}

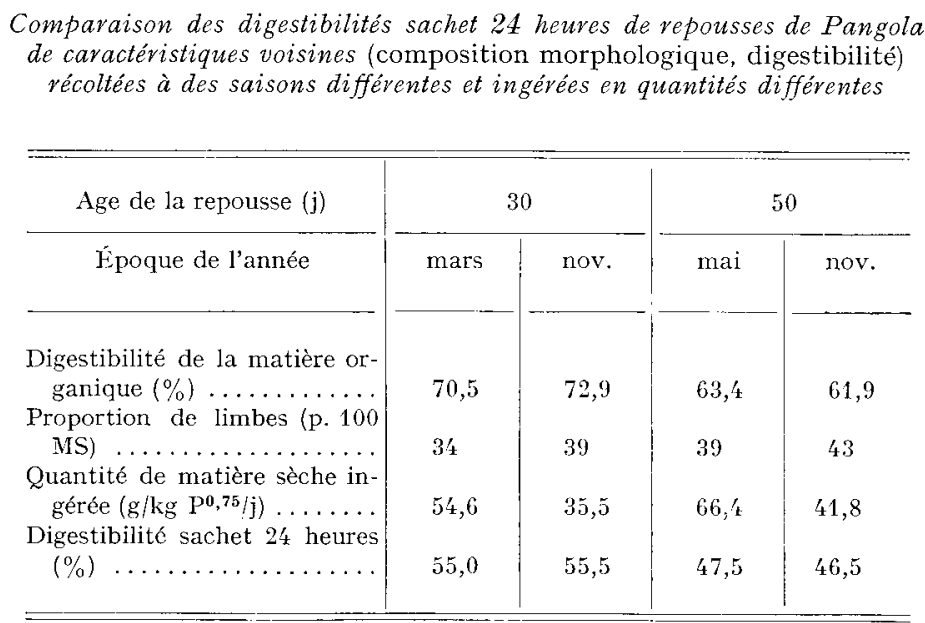

- Nous avons voulu voir, à partir de 22 échantillons de caractéristiques différentes, si l'ingestibilité était en liaison avec la vitesse de dégradation de la plante dans le rumen estimée par le pourcentage de matière sèche disparue au bout d'un séjour de 24 heures dans le rumen (digestibilité sachet 24 heures) : les quantités de matière sèche ingérées n'ont présenté aucune liaison avec la digestibilité sachets 24 heures. Pour mieux vérifier cette absence de liaison nous avons considéré deux 
groupes de 4 repousses de digestibilité et de composition morphologique et chimique comparables mais récoltées à des saisons différentes et ingérées en quantités très différentes (tabl. 4) à l'intérieur de chaque groupe : 42 et 69 d'une part et 35 et $59 \mathrm{~g} / \mathrm{kg} \mathrm{P}^{0,75}$ d'autre part. L,e pourcentage de matière sèche disparue au bout de 24 heures a été le même pour un groupe donné et a donc été indépendant des quantités de matière sèche ingérées.

Les coefficients de corrélation liant la quantité de matière sèche ingérée à la teneur en matière sèche, à la composition chimique (MA'T et cellulose brute de Weende) à la proportion de limbes, à la digestibilité de la matière organique et à la digestibilité sachets $24 \mathrm{~h}$ ont été compris entre 0,073 (teneur en matière sèche) et 0,427 (digestibilité de la matière organique). Ils sont donc très faibles et la quantité de matière sèche ingérée ne peut pas être prévue de manière suffisamment précise à partir de ces critères simples.

Tout semble donc se passer comme si les facteurs liés à la plante étaient peu responsables des variations de la quantité de matière sèche ingérée.

Contrairement aux fourrages tempérés et aux résultats de ARRoyo-AGUII,U et al. (I963) obtenus sur quelques fourrages tropicaux, il n'est par conséquent pas possible de prévoir de manière satisfaisante la valeur alimentaire qui est le produit de la quantité volontairement ingérée par la digestibilité et seule la digestibilité peut être prévue de manière suffisamment précise.

Quantités de matière organique digestible ingérées

Les quantités de matière organique digestible ingérée varient dans le cas des repousses d'âge variable entre les valeurs moyennes de 24,0 à 77 jours et à $35,9 \mathrm{~g} / \mathrm{kg}$ $\mathrm{P}^{\mathbf{0}, 75}$ à 28 jours (valeurs extrêmes comprises entre $\mathrm{I} 7,5$ et $45, \mathrm{I}$ ) (tabl. 2) ; dans le cas des repousses d'âge constant elles sont de 26,8 et $26,9 \mathrm{~g} / \mathrm{kg} \mathrm{P}^{\mathbf{0}, 75}$ respectivement à $30 \mathrm{j}$ et à $50 \mathrm{j}$ et ne diffèrent donc pas suivant 1'âge.

Elles présentent les mêmes variations saisonnières que les quantités de matière sèche ingérées et sont maximum pendant les mois de mars à mai et minimum pendant les mois d'août à décembre.

\section{Valeur énergétique nette}

Nous 1'avons exprimée en UF Breirem (BREIREM, I954)

$$
\mathrm{UF} / \mathrm{kg} \mathrm{MS}=\frac{2,36 \mathrm{MOD}(\mathrm{g} / \mathrm{kg})-\mathrm{I}, 20 \mathrm{MO} \text { indigestible }(\mathrm{g} / \mathrm{kg})}{\mathrm{I} 63^{2}}
$$

où MOD est la matière organique digestible et MO indigestible la matière organique indigestible. Ce mode de calcul ayant été défini pour des climats tempérés, il convient donc d'utiliser avec réserve les chiffres présentés dans le tableau 2. Ceux-ci permettent cependant d'effectuer un classement en valeur relative.

La valeur énergétique nette a varié de 0,82 à 0,43 UF (valeurs extrêmes) et a diminué de 0,73 UF à 28 jours à 0,52 UF à 77 jours (valeurs moyennes) soit une diminution de 0,004 UF par jour.

\section{Indices des quantités ingérées et de valeur alimentaire.}

Pour comparer la valeur alimentaire des repousses de Pangola entre elles nous avons calculé l'indice des quantités ingérées et l'indice de la valeur alimentaire 
(tab1. 2) en utilisant la méthode de calcul de DEMARguili.y et WEIss (I970) proposée pour des fourrages tempérés. L'indice Ioo des quantités ingérées qui est égal à $70 \mathrm{~g} / \mathrm{kg}$ $\mathrm{P}^{0,75}$ représente la moyenne des quantités ingérées obtenues sur les fourrages tempérés. L'indice roo de valeur alimentaire est égal à $70 \mathrm{~g} \times 0,72 \mathrm{UF}$ soit $0,05 \mathrm{UF}$ ingérées par $\mathrm{kg}$ de poids métabolique; $0,7^{2} \mathrm{UF}$ représentant la valeur moyenne obtenue sur les fourrages tempérés. Cette méthode nous permet donc en même temps de comparer la valeur alimentaire du Pangola à celle des fourrages tempérés. L'indice de valeur alimentaire moyen, qui est toujours faible (valeur maximum de $8 \mathrm{I}$ ), diminue presque de moitié lorsque l'âge de la plante passe de 28 à 77 jours.

\section{Production à l'hectare}

Nous avons regroupé dans la figure 6 les variations, suivant 1'âge, de la production de matière sèche, d'unités fourragères et de matières azotées digestibles par hectare_en séparant les deux saisons de faible et de forte croissance de la plante.
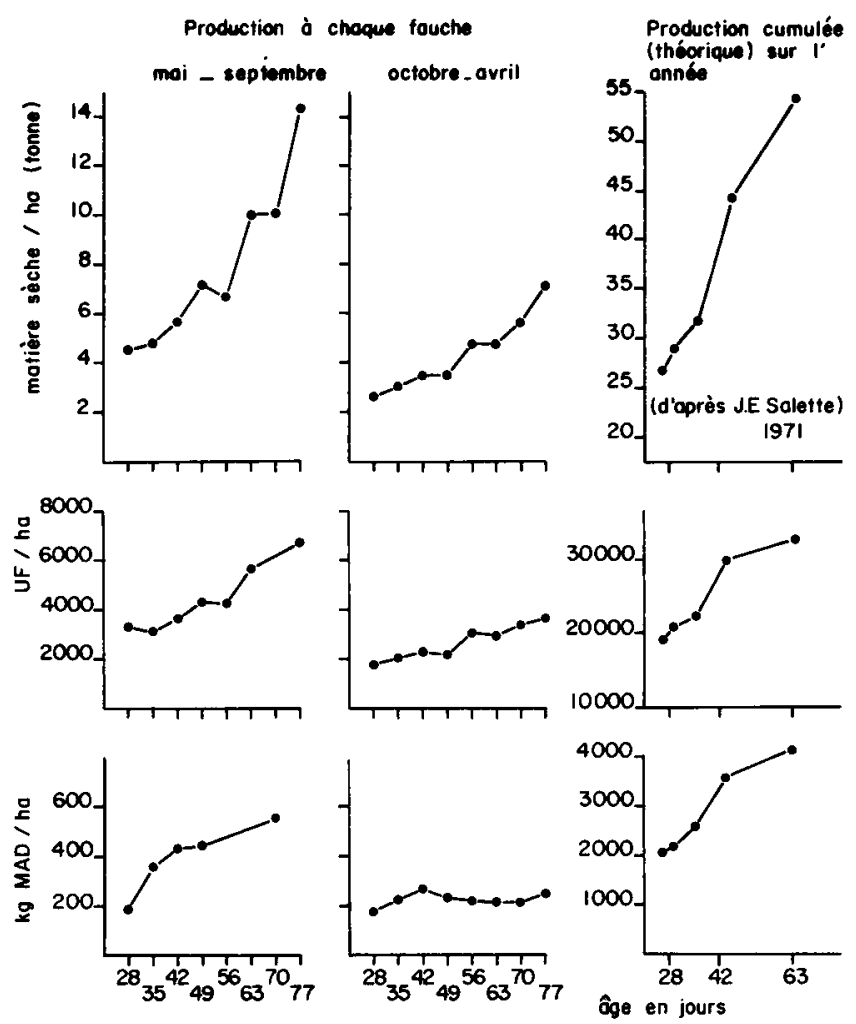

Fia. 6. - Production de matière sèche, d'unités fourragères et de matières azotées digestibles par hectare à chaque fauche pendant les saisons de forte et de faible croissance, cumulée sur l'année suivant l'intervalle de fauche

Les quantités d'UF et de MAD sont très élevées et varient entre des valeurs extrêmes relativement moins grandes que les quantités de matière sèche produites. L'augmentation avec l'âge de la repousse des quantités d'UF produites à chaque 
fauche est plus importante pendant la saison de forte croissance de la plante, saison où, malheureusement, la teneur en matières azotées et la quantité ingérée sont les plus faibles.

C'est également pendant cette saison que les différences dans les quantités d'UF et de MAD produites dues à l'âge sont les plus marquées alors qu'elles sont relativement faibles pendant la saison de faible croissance.

Les quantités totales d'unités fourragères produites par an à l'hectare sont un peu plus élevées avec un rythme d'exploitation de 50 jours et une fumure de $350 \mathrm{~kg}$ d'azote par ha et par an (I4 500 UF) qu'avec un rythme d'exploitation de 30 jours et une fumure de $800 \mathrm{~kg}$ d'azote (I2 $800 \mathrm{UF}$ ). Au contraire les quantités globales de matières azotées digestibles produites par hectare sont plus élevées avec les repousses exploitées jeunes et bien fertilisées $(2085 \mathrm{~kg} / \mathrm{ha}$ dans le cas des repousses de 30 jours contre I $420 \mathrm{~kg} / \mathrm{h}$ a dans le cas des repousses de 50 jours).

\section{DISCUSSION}

\section{Valeur alimentaire}

I1 ressort de l'ensemble de ces résultats que,"même exploité suivant des rythmes rapides et recevant des niveaux de fertilisation élevés, le Pangola n'a jamais une valeur alimentaire très élevée. La teneur en cellulose Weende des jeunes repousses n'est jamais inférieure à $30 \mathrm{p}$. Ioo et la teneur en matières azotées digestibles est rarement supérieure à $\mathrm{I} 2 \mathrm{p}$. roo. La digestibilité de la matière organique quant à elle ne dépasse que très rarement $7^{2} \mathrm{p}$. Ioo. L'hypothèse (DEInum et al., I968) (MINSON et MCLEOD, I970) selon laquelle le climat aurait une action dépressive sur la digestibilité des espèces fourragères tropicales en modifiant la physiologie de la plante mérite de retenir particulièrement l'attention. Ces plantes, dès les premières semaines de repousse, élaborent très vite des membranes qui se lignifient rapidement. Ainsi, dès que leur exploitation est possible, nous sommes déjà en présence d'un matériel physiologiquement âgé dont la đécroissance ultérieure de la valeur nutritive avec l'âge est alors plus régulière et moins rapide que dans le cas des espèces tempérées.

C'est vraisemblablement la raison pour laquelle 1'âge ou l'avancement du stade de croissance n'ont pas une influence sur la composition morphologique, sur la digestibilité de la matière organique et sur la teneur en matières azotées digestibles, aussi grande que chez les espèces tempérées. Cette constatation est d'ailleurs à rapprocher des résultats obtenus par Grieve et Osbourn (I965) et SHERrod et Ishizakr (I967) sur Pangola et par HAGGAR et AHMED (r97o) sur Andropogon gayanus, desquels une influence de l'âge ne se dégage pas de façon très marquée. L'âge de la repousse a malgré tout une influence plus nette sur la digestibilité de la matière organique pendant la saison de forte croissance mais toutefois moins importante que celle notée par BLYDENSTEIN et al., I969, à Costa Rica où les conditions climatiques sont pourtant voisines des nôtres. L'âge a surtout une action marquée sur la teneur en matières azotées totales (BUTT'ERWOR'TH et al., I96I ; VICENTE-CHANDLER et al., I96I ; SALETTE, I97I ; ThOMAS et McLAREN, I97I).

Il est indispensable d'ailleurs de dissocier les deux saisons caractéristiques tant dans l'analyse du comportement de la plante et de l'élaboration de son rendement 
(DEGRAS, I968; SALETTE, I970) que dans la recherche des facteurs de variation de sa valeur nutritive. A âge donné la digestibilité de la matière organique présente peu de variations saisonnières alors que la teneur en matières azotées en présente d'importantes. Pendant la saison de forte croissance la plante se comporterait plus comme une graminée de type tempéré effectuant son premier cycle de végétation et épiant, alors que pendant la saison de repos son comportement serait plus à rapprocher de celui d'une repousse feuillue. La digestibilité des tiges est alors en effet assez voisine de celle des feuilles, ce qu'observent d'ailleurs également HAGGAR et Ahmed (I970) sur Andropogon, et cela sans doute en raison de l'accumulation de réserves sous forme de saccharose (HunTER et al., I970) ; il en résulte que la variation respective des proportions de feuilles et des tiges influence peu ou pas la digestibilité. Il n'en est pas de même de la teneur en azote qui, étant plus importante dans les feuilles, évolue parallèlement à la proportion de ces dernières dans la plante.

Les variations des quantités ingérées, qui sont très importantes, résultent à la fois de l'évolution de l'ingestibilité de la plante au cours de son cycle de croissance et au cours de l'année et de l'action du climat sur l'appétit des animaux. Il est toutefois difficile de dégager l'importance respective de ces deux facteurs.

La diminution de l'ingestibilité du fourrage au cours du cycle de croissance s'explique par les mécanismes normaux de la régulation de l'appétit chez les ruminant: la masse de membranes ingérées que reflète la quantité de cellulose brute ingérée est en effet relativement constante (tabl. 2). Comme la teneur en cellulose brute (membranes) augmente avec l'âge il est logique que l'aptitude de la plante à être ingérée diminue.

Comme l'indiquent BUTTERworth et al. (I96I) les variations saisonnières traduisent essentiellement l'influence directe des facteurs climatiques sur l'appétit des animaux. La température et l'humidité modifient en effet la régulation thermique et, par là l'appétit (WORSTEl, et Brody, I953 ; FINDLAY, I954, cités par PAYNE, ig66; Sharma, ig68). Cependant même si, comme le notent, Mriford et Mrnson, I965, Johnson et al, I968, la teneur en eau et les caractéristiques chimiques et morphologiques de la plante ou encore, dans notre cas, sa facilité de dégradation dans le rumen peuvent difficilement être reliées aux quantités ingérées, une partie des variations saisonnières des quantités ingérées doit être due à la diminution de son ingestibilité. Les plantes de juin, juillet et aôtut (saison de forte croissance) ont en effet une teneur plus faible en azote (tabl. 3) et une proportion plus élevée de tiges + gaines et de membranes (fig. I) qui peuvent certainement rendre compte en bonne partie de la quantité ingérée plus faible à cette période.

Comme les variations de la digestibilité et de l'ingestibilité dues à l'âge et au vieillissement de la plante sont toutefois relativement peu importantes, ce sont surtout les variations des quantités ingérées liées à la saison et la variation de la teneur en matières azotées qui vont être responsables des quantités d'éléments nutritifs ingérées par l'animal. Malheureusement c'est pendant les mois de février à mai, époque à laquelle le Pangola qui n'a pas encore repris son rythme élevé de croissance produit peu, que les quantités de matière sèche volontairement ingérées sont les plus élevées.

Il est sans doute possible d'augmenter la valeur nutritive đu Pangola grâce à une fertilisation plus poussée ; c'est ainsi qu'en augmentant de o,7o kg la quantité d'azote par jour de végétation 1'indice de valeur alimentaire des repousses de 50 jours 
passe de 52 à 64 et cela grâce à l'augmentation de la digestibilité de la matière organique, augmentation que l'on n'observe pas en climat tempéré (BLASER, I964; Demarquili.y, I970). On sait déjà (VICENTE-ChaNdLER et al., I96I ; SaletTe, I970) que la réponse de la production de matière sèche à la fertilisation est très importante mais les données relatives à son influence sur la digestibilité sont à notre connaissance très rares pour les fourrages tropicaux. FRIBOURG et al. (I97I) constatent une augmentation sensible de la digestibilité in vitro de Cynodon dactylon E. PERs. avec le niveau de fertilisation azotée; nous observons (CHFNost, résultats non publiés) une influence de l'azote sur la digestibilité $i n$ vivo et in vitro de Digitaria pentzii 752 et de Panicum maximum alors que CARo-CosTas et al. (1972) n'enregistrent pas d'effet de la fertilisation azotée sur la croissance des génisses pâturant du Pangola.

\section{Conséquences pratiques}

Compte tenu de ces éléments, quel peut être le type d'exploitation permettant d'obtenir le plus de matière organique et azotée digestible par unité de surface sous forme d'un fourrage dont la teneur en matière.; azotées digestibles et l'indice de valeur alimentaire soient acceptables?

- pendant la saison de forte croissance :

la quantité de matière sèche produite à l'hectare augmentant rapidement avec l'âge et avec le niveau de fertilisation, il paraît plus intéressant dans une optique d'affouragement en vert d'exploiter à un stade relativement avancé une prairie qui a reçu tune forte fumure et qui produit des quantités importantes d'unités fourragères (fig. 6). La faible ingestibilité serait compensée par l'influence bénéfique de la fumure sur la digestibilité. La teneur en matières azotées, de toutes façons très faible à cette époque, le serait même si le fourrage était exploité à un stade jeune (fig. I). Cela serait toutefois difficilement envisageable dans une optique d'exploitation par le pâturage en raison dés refus et du piétinement effectués par les animaux (notamment les vaches laitières) d'autant plus important que l'herbe pâturée est plus haute (Vivier, Chenost, résultats non publiés).

- pendant la saison de faible croissance:

la quantité de matière sèche produite à l'hectare augmentant peu avec l'âge de la repousse et le niveau de fertilisation, les quantités d'unités fourragères produites à l'hectare sont à peu près indépendante:s de l'âge (fig. 6). L'exploitation à des stades plus jeunes, qui ne nuirait donc pas à la production totale d'unités fourragères, permettrait en revanche d'exploiter un fourrage dont la teneur en azote serait la plus élevée de l'année, la quantité totale de matières azotées digestibles produite par hectare à cette époque dépendant de toute façon peu de l'âge de la repousse. Cette fréquence plus rapide d'exploitation permettrait en outre d'éviter, selon nos collègues entomologistes, les infestations de pucerons (Sypha flava FORBES) que l'on observe en fin de saison humide à partir de janvier-février sur les prairies dont le rythme de fauche est lent. En outre, les pertes dues au feutrage de la plante seraient plus réduites.

Il est évident que ce schéma suppose, pour subvenir aux besoins d'une charge d'animaux constante tout au long de l'année, d'effectuer des reports de récolte de la saison de forte croissance sur la saison de faible croissance. Ce report peut être effectué en climat tropical humide sous forme d'ensilage. On peut également insérer 
dans le système fourrager des espèces pouvant intervenir à contre saison, telles que les hybrides Sorgho Sudan (Graxier et BIGot, I97I ; Bousque'T, I97I) et les Panicum maximum ou autres graminées soumises à un rythme saisonnier de croissance différent de celui du Pangola.

En conclusion le Pangola, comme les principales graminées fourragères tropicales, a une valeur alimentaire faible. Il est certes possible d'améliorer sa digestibilité mais surtout sa teneur en azote par une fertilisation azotée élevée et par un rythme d'exploitation rapide. Toutefois 1'avantage retiré de ce dernier sur le plan de la valeur alimentaire est malheureusement sans commune mesure avec le " manque à gagner " dans la production de matière sèche. De toute façon les quantités d'aliment concentré qu'il est nécessaire de distribuer à des animaux en production consommant des repousses de Pangola exploitées même à des stades jeunes restent très élevées (Chenost et Bousquet, I974). Une certaine souplesse dans 1'exploitation du Pangola peut donc être admise.

Grâce à sa facilité d'implantation et d'exploitation, à sa potentialité de production très élevée et à sa pérennité intéressante, cette plante constitue un atout majeur dans le développement de l'élevage aux Antilles.

Reçu pour publication en janvier 1975.

\section{SUMMARY}

\section{FACTORS AFFECTING FEEDING VALUE \\ OF PANGOLA GRASS (DIGITARIA DECUMBENS, STENT) \\ IN A HUMID TROPICAL, CLIMATE}

Variation in chemical and morphological composition, digestibility, and voluntary intake by goats, of Pangola grass (Digitaria decumbens) regrowths was studied over two and a half years in a humid tropical climate ( $3 \mathrm{~m}$ rainfall per year).

I) Digestibility was measured with Alpine male goats fed with fresh Pangola grass according to two systems :

- One group of goats received throughout the year Pangola herbage of variable age. The period of $2 \mathrm{I} / 2$ years was divided into $\mathrm{I} 2$ cutting cycles and the field was trimmed over and supplied with $80 \mathrm{~kg}$ nitrogen and $80 \mathrm{~kg}$ potassium at the beginning of each cycle. Phosphoric acid was applied once a year only.

- Two other groups of goats received herbage of constant age. For one group the herbage was 30 days old and for the other it was 50 days old. This herbage was obtained from two fields divided into daily cutting plots. The fields, cut repeatedly over 18 months received respectively $84^{\circ} \mathrm{kg} \mathrm{N}, 250 \mathrm{~kg} \mathrm{P}, 84^{\circ} \mathrm{kg} \mathrm{K}$ and $35^{\circ} \mathrm{kg} \mathrm{N}, \mathrm{I}_{30} \mathrm{~kg} \mathrm{P}, 35^{\circ} \mathrm{kg} \mathrm{K}$. Nitrogen and Potassium were applied after each cut, Phosphoric acid only once a year.

2) The following parameters were determined : a) morphological composition : p. roo leaf blades, p. Ioo stems and leaf sheaths, p. Ioo ears p. Ioo dead material ; $b$ ) p. Ioo ash, p. Ioo protein and Weende crude fibre contents. The samples were representative of the measurement periods of 6 days, each of which was separated from the following by one day.

In addition, the $48 \mathrm{~h}$ in vitro digestibility and the $24 \mathrm{~h}$ and $72 \mathrm{~h}$ bag digestibilities were measured on 24 samples representative of plants harvested at different seasons.

3) The results are given in tables $I$ and 2 .

4) The average crude protein level varies from $5 . \mathrm{I}$ to $x 6.5 \mathrm{p}$. 100 according to age and season. The influence of age varies with the season. The greatest influence of age and the highest crude protein contents (fig. I) are observed during the periods of slowest growth. The crude protein content is correlated with the proportion of leaf blades $(r=0.675)$. 
5) The percentage of stems + sheaths is high, even in young regrowths, particularly during the period of rapid growth, and alters little with age. The percentage of leaf blades is high during the period of slow growth decreases with age owing to death of the blades.

6) Weende crude fibre content is always very high and varies within fairly narrow limits $(29.7$ to 40.3$)$.

7) The average organic matter digestibility varies from 70.8 for 28 days old herbage to 59.5 for 77 days old herbage. The regression of digestibility on age is represented by the following equation :

$$
\mathrm{Y}=77 . \mathrm{I9}-0.2 \mathrm{I} 7 \mathrm{X} \pm 3.09 \quad(r=0.709 ; n=67)
$$

The reduction in digestibility is greatest during the season of rapid growth. This results from diminution in the digestibility of the stems + sheaths fraction, rather than from an increase in the size of this fraction.

A higher level of nitrogen manuring in the variable age system increases digestibility by 5 p. Ioo compared with the constant age system.

The in vivo digestibility is correlated with the proportion of leaf blades $(r=0.539, n=$ I 53 ) but only very loosely with the dry matter content of the plants $(\gamma=0.309)$. It is also correlated with the $4^{8} \mathrm{~h}$ in vitro digestibility and particularly with the $72 \mathrm{~h}$ bag digestibility $(r=0.8 \mathrm{I} 8$, $n=24$ ), but correlation is still not as close as that found with temperate climate herbage.

The digestible crude protein content $(y)$ is very closely corrclated with the total crude protein content $(x)$ :

$$
\mathbf{Y}=0.9 \mathrm{I} 6 \mathrm{X}-2.895 \pm 0.495 \quad(r=0.989, n=\mathbf{I} 83)
$$

8) Net energy, expressed in FU and estimated by the Breirem formula, varies from 0.73 at 28 days to 0.52 at 77 days.

9) The dry matter intake varies according to season and age of herbage (table 3 ), the influenco of age varying with the season. Variations due to season are greater than those due to age (CHENOST: 1972). The voluntary dry matter intake is the greatest from February to April.

This variation in voluntary intake cannot be explained by variations in the rate of forage digestion in the rumen (table 4 ), or in the total dry matter intake, or in the percentage dry matter, or in its digestibility, or in the percentage of leaf blades. It appears, therefore, that the variations in dry matter intake are very little dependant on the plant characteristics.

ro) Maximum production per hectare of dry matter, fodder units and digestible crude protein occurs during the rapid growth season (fig. 6), when crude protein contents are lowest, but least variable with herbage age and when, unfortunately, the intake of nutrients is smallest.

Expressed in $\mathrm{FU}$ yield per hectare is greater in the case of old herbage, even when poorly fertilized. Production of crude protein is highest in young, well fertilized herbage.

II) The feeding value of Pangola grass is relatively low, even if cut frequently and well fertilized and it depends considerably on climatic factors, which probably affect the animals directly.

I2) Consequently, it appears better to take advantage of the high productivity of this species rather than to attempt to improve its feeding value by cutting very young. Thus, during the intensive growth season, when the percentage digestible crude protein varies little with herbage age, it appears desirable to harvest at infrequent intervals in order to obtain high UF values per hectare. In contrast, during the season of reduced growth, cutting at an earlier stage would supply forage with a higher digestible crude protein content.

However, the amount of grass really utilized must be taken into account. Although such a system might well be useful with zero grazing, trampling of tall grass could restrict direct grazing.

\section{RÉFÉREINCES BIBLIOGRAPHIQUES}

Arroyo-Aguilu J. A., Evans J. L., Taylor M. W., ig63. The artificial rumen technique for estimating the nutritive value of forages. J. A gron. University Puerto-Rico, 47, I69-179.

BLASER R. E., I 964 . Symposium on forage utilization : effects of fertility levels and stage of maturity on forage nutritive value. J. Anim. Sci., 23, 246-253.

Blydenstein J., Louis S., Toledo J., Camargo A., I969. Productivity of tropical pastures. I. Pangola grass. J. Brit. Grassl. Soc., 24, 7I-75. 
Bousouet P., 197r. Conduite de l'élevage bovin sur prairie de Pangola (Digitaria decumbens) en zone à saison sèche marquée aux Antilles Françaises. Proc. Colloque sur la production des fourrages et leur uilisation par les ruminants. Guadeloupe 24-29 mai.

BreIREM K., 1954. Die Nettoenergie als grundlage der bewertung der futtermittel, in : NeHring K., 100 jahre Möchern. Die bewertung der futterstoffe und andere probleme der Tiernährung. Berlin Deutsche Akad. der Landwirtschaftswissenchaften, t. II, 97-I08.

Butterworth M. H., Groom C. G., Wilson P. N., ig6r. The intake of Pangola grass under wet and dry season conditions in Trinidad. J. Agric. Sci., 56, 407-410.

Butterworth M. H., Ig64. The digestible energy content of some tropical forages. J. Agric. Sc., 64, 319-32I.

Butterworth M. H., Butterworth J. P., I965. Some aspects of the utilization of tropical forages. II. Pangola and coastal Bermuda hays. J. Agric. Sci., 65, 389-395.

Caro-Costas R., Vicente-Chandler J., Abruna F, i 972 . liffects of four levels of fertilization on beef production and carrying capacity of Pangola grass pastures in the humid mountains region of Puerto-Rico. J. A gric. Univ. Puerto-Rico, 56, 2 19-22z.

Chenost M., ig72. Observations préliminaires sur les variations saisonnières de la quantité d'aliments ingérée par les caprins en milieu tropical humide. Ann. Zootech., 21, I I3-I 20.

Chenost M., Bousguet P., 1974. Exploitation en vert du Pangola pow la production de lait par des chèvres. I. Alimentation complémentaire suivant la qualité du fourrage. Ann. Zootechn., 23, 45-62.

Degras L., I968. Introduction et étude des variétés de Digitaria aux Antilles. Ann. Amél. Pl., 18, I39I69.

Deinum B., Van Es A. J. H., Van Soest J. P., I968. Climate, nitrogen and grass. II. The influence of light intensity, temperature and nitrogen on in vivo digestibility of grass and the prediction of these effects from chemical procedures. Neth J. Agric. Sci., 16, 217-223.

Demargutlly C., Chenost M., I969. Etude de la digestion des fourrages dans le rumen par la méthode des sachets de nylon. Liaisons avec la valeur alimentaire. Ann. Zootech., 18, 4r9-436.

Demarouilly C., ig7o. Influence de la fertilisation azotée sur la valeur alimentaire des fourrages verts. Ann. Zoolech., 19, 423-437.

Demarouily C., Weiss Ph., I97o. Tableaux de la valeur alimentaire des fourrages. SEI, étude $n^{\circ} 42$ M3 Four-53, Po Elev. 3 II.

Fribourg H. A., EDwards N. C., Barth J. R., K., I97I. In vitro Dry-Matter digestibility of "Midland Bermuda grass grown at several level of N fertilization. A gron. Journal, 63, 786-788.

Granter P., Bigot A., i97r. La culture des sorghos fourragers à Madagascar. Utilisation à contre saison. Rev. Elev. Méd. V'ét. Pays Tropicaux, 24, I25-136.

Grieve C. M., Osbourn D. F., ig65. The nutritional value of some tropical grasses. J. Agric. Sci., 63, $253-259$.

Haggar R. J., Ahmed M. B., ig7o. Seasonal production of Andropogon gayanus. II. Seasonal changes in digestibility and feed intake. J. Agric. Sci., 75, 369-373.

Holmes J. C., Lang R. W., I963. Effect of fertilizer nitrogen and herbage dry matter content on herbage intake and digestibility in bullocks. Anim. Prod., 5, r7-26.

Huang Chia Yeh T. P., i965. Chemical composition of Pangola grass in relation to its maturity. Proc. 9ih Intern. Grassl. Cong., $\mathbf{5 4 6 .}$

Hunter R. A., McIntyre B. L., McIlroy R. J., I97o. Water-soluble carbohydrates of tropical pasture grasses and legumes. J. Sci. Food A gric., 21, 400-405.

Johnson W. L., Hardison W. A., Ordoveza A. L., Castillo L. S., ig68. The nutritive value of Panicum Maximum (Guinea grass). III. Factor affecting voluntary intakes by cattle and water buffaloes. J. Agric. Sci, '71, 67-71.

Milford R., Minsoy D. J., I965. Intake of tropical pasture species. 9th Internat. Grassl. Congr., 236.

Milford R., Misson D. J., 1965. The relation between the crude protein content and the digestible crude protein content of tropical pastures plants. J. Brit. Grassl. Soc., 20, I77-I79.

Mrsson D. J., McLeod N. M., I97o. The digestibility of temperate and tropical grasses. Proc. 11th Intern. Grassl. Congr., 719-722.

OAKes A. J., 1960. Pangola grass in the Caribbeans. Proc. 8th Intern. Grassl. Congr., 386-389.

Osboukn D. F., 1969. The introduction of Pangola grass in the Caribbean islands. J. Brit. Grassl. Soc., 24, 76-80.

Payne W. J. A., I966. Nutrition of ruminants in the tropics. Nutr. Abstr. Rev., 33, 653-67o.

Salette J. E., I970. Nitrogen use and intensive management of grass in the wet tropics. Proc. 11th. Inter. Grassl. Congr., 404-407.

Salette J. E., I9לr. Les aspects saisonniers de la croissance des graminées fourragères; incidences sur la qualité ; influence des conditions de milieu. Miméo. Journées techniques sur la production fourragère et l'élevage des ruminants. Guadeloupe, Martinique, I9-22 janvier.

SHARMA D. C., I968. Intake and digestion of nutrients by the bovines under climatic stress. J. Nutr., 94, $317-325$.

Sherrod L. B., Ishizaki S. M., I967. Effects of stage of regrowth and location upon the nutritive value of Kikuyu and Pangola grass. (Abstr.) J. Anim. Sci., 26, 938. 
Thomas O. A., Mclaren L. E., r97r. Some studies on the digestibility of Pangola grass (Digitaria. decumbens stent) in Jamaica. Trop. Agric. Trinidad, 48, 225-235.

Tilley J. A. M., Terry R. A., 1963. A two technique for in vitro digestion of forage crops. J. Brit. Grassi. Soc., 18, I04-III.

Vicente-Chandler J., Figarella J., Sila S., ig6r. Effects of nitrogen fertilization and frequency of cutting on yield and composition of Pangola grass In Puerto-Rico. J. Agric. Univ. Puerto-Rico, 45, $37-45$.

Vicente-Chander J. R., et al., I964. The intensive management of tropical forages in Puerto-Rico. Bull. 187, Univ. of Puerto Rico, 5- I52. 